\title{
Organic and Inorganic Carbon Isotope in Cenozoic Source Rocks of the Qaidam Basin (China)
}

S. X. ZHOU ${ }^{1}$, J.LI ${ }^{1}$, K. F. CHENG ${ }^{1}$, C. ZHANG ${ }^{1}$, Z.X SUN $^{1}$, P.P. LI $^{1}$ AND B. K. MENG

${ }^{1}$ Northwest Institute of Eco-Environment and Resources, Chinese Academy of Sciences, Lanzhou 730000

(*correspondence:sxzhou@1zb.ac.cn)

The Qaidam Basin is located in the northern margin of the Tibetan Plateau, which is typical Cenozoic sedimentary basin of inland saline lake facies. Its sedimentary strata consists of mudstones, calcareous mudsones, marls interclating siltstone, gypsum and rock salt beds, there are abundant Tertiary petroleum resources in this Basin. In this study, cenozoic source rocks from petroleum drilling cores of different Cenozoic stratigraphic Formation were collected and analysed on carbon and oxygen isotope of carbonates, total organic carbon isotope and $\delta^{13} \mathrm{C}$ values of n-alkane and iso-alkane and conventional biomarker on source rock extracts. $\delta^{13}$ CPDB values of carbonate range from 8.0 to $1.1 \%$, with the average value of $-2.5 \%$, while $\delta^{18} \mathrm{OPDB}$ values range in $-11.7 \%$ to $-0.8 \%$, with the average value of $6.9 \%$. This maybe show that the Cenozoic lacustrine carbonates are formed in semi-open and semi-closed saline environments.

The contents of organic carbon is in the range of 0.16$2.51 \%$, and the contents of ${ }^{13} \mathrm{C}$ in organic matter from Cenozoic source rocks range from -21.3 to $-31.1 \%$, and average of $24.8 \%$ o. Meantime, n-alkane $\delta^{13} \mathrm{C}_{29}$ ranging from-21.8 to-36.5\%o (average of $-30 \%$ ) and $\delta^{13} \mathrm{C}_{31}$ (values of -24.1 to $38.6 \%$ ), these isotopic signatures showed that $\mathrm{C}_{3}$ Plants are the main dominant vegetation around ancient Qaidam salt lake from the Eocene to Upper Pliocene.

Recently, the carbon isotope of molecular fossil phytane is tried to use reconstructing secular trends of $P_{\mathrm{CO} 2}$, but our data shows that $\delta^{13} C_{\text {phytane }}$ range from -37.5 to $-20.7 \%$ in Cenozoic strata decreasing from Eocene to pleistocene, which appear to conflict with trend in marine sediments and oils. It can be seen that more work need to do for quantitative estimates of atmospheric $P_{\mathrm{CO} 2}$ in terrestrial and lacustrine settings.

This work was supported by partly by the Chinese National Natural Science Foundation $(41872147,41072105)$, the Chinese National Major Fundamental Research Developing Project ((2016ZX05003002-004) 